\title{
Uptake of selected PAHs from contaminated soils by rice seedlings (Oryza sativa) and influence of rhizosphere on PAH distribution
}

\author{
Yu-Hong Su ${ }^{\text {a }}$, Yong-Guan Zhu ${ }^{\text {b,* }}$ \\ ${ }^{\text {a }}$ Chemistry Department, Xinjiang University, Urumqi 830046, China \\ ${ }^{\mathrm{b}}$ Research Center for Eco-environmental Sciences, Chinese Academy of Sciences, 18 Shuangqing Road, Beijing 100085, China
}

Received 17 May 2007; received in revised form 24 October 2007; accepted 8 November 2007

Contributions of plant uptake and rhizosphere effect on removal of PAHs from soils are relatively insignificant.

\begin{abstract}
The uptake of selected polycyclic aromatic hydrocarbons (PAHs) by rice (Oryza sativa) seedlings from spiked aged soils was investigated. When applied to soils aged for 4 months, naphthalene, phenanthrene, and pyrene exhibited volatilization loss of 98, 95, and 30\%, respectively, with the remaining fraction being fixed by soil organic matter and/or degraded by soil microbes. In general, concentrations of the three PAHs in rice roots were greater than those in the shoots. The concentrations of root associated PHN and PYR increased proportionally with both soil solution and rhizosphere concentrations. PAH concentrations in shoots were largely independent of those in soil solution, rice roots, or rhizosphere soil. The relative contributions of plant uptake and plant-promoted rhizosphere microbial biodegradation to the total mass balance were 0.24 and 14\%, respectively, based on PYR concentrations in rhizosphere and non-rhizosphere soils, the biomass of rice roots, and the dry soil weight.
\end{abstract}

(C) 2007 Elsevier Ltd. All rights reserved.

Keywords: PAHs; Rice (Oryza sativa); Uptake; Rhizosphere effect; Aged soil

\section{Introduction}

Sources of polycyclic aromatic hydrocarbons (PAHs) in the environment include naturally occurring deposits, incompletecombustion products of fossil fuels and biomasses, and from oil refinery and petrochemical spills (Shor et al., 2004). Due to carcinogenic, mutagenic, and teratogenic properties (Brady et al., 2003), their occurrence frequency (Jones et al., 1989; Wennrich et al., 2002; Tao et al., 2004) and their environment persistence (Fismes et al., 2002; Bi et al., 2003), PAHs are of a particular concern to human and environmental health. Conceivably, plants could be exploited to aid in the removal of PAHs and other contaminants from soils via two main mechanisms: (1) the accumulation by, and the subsequent metabolism in, plant tissues following the contaminant uptake by

\footnotetext{
* Corresponding author.

E-mail address: ygzhu@rcees.ac.cn (Y.-G. Zhu).
}

plant roots (Fismes et al., 2002; Wild et al., 2005) and (2) the enhanced microbial activity induced by root exudation of enzymes to transform and/or mineralize contaminants (Rentz et al., 2004; Kamath et al., 2005). Thus, the bioavailability of soil associated PAHs and plant uptake capacity would greatly influence the efficiency of PAH phytoremediation.

Analyses of the levels of nonionic contaminants in plants in relation to the external levels in water (or soil water) from extensive sources have revealed that these contaminants enter plants largely via passive process (i.e., partition; Briggs et al., 1982; Chiou et al., 2001; Trapp, 2004; Su and Zhu, 2006). In plantwater-soil systems, the low water solubilities and high partition coefficients of PAHs result in minimal PAH levels in external or pore water, especially with soils of high sequestration abilities, which limit subsequent PAH availability for plant uptake. Root concentration factor, shoot concentration factor, and transpiration stream concentration factor (Briggs et al., 1982) have been frequently been used to model plant uptake and translocation. 
Other studies have meanwhile revealed that the extent of plant assisted PAH removal from soil decreases with soil contact time (MacLeod and Semple, 2000; Reid et al., 2000). Generally, aged PAHs are found to be less microbially bioavailable due to an increased binding to soil organic matter (Northcott and Jones, 2001; Nam and Kim, 2002). Specifically, an increased association with the soil humin fraction (the insoluble fraction of the humic substance) has been shown to be a main cause for decreased biodegradation (Nam and Kim, 2002). Due to the limitations of mass transport with aging, total soil associated contaminant concentration is not regarded as reliable indicators of bioavailability (Alexander, 2000). Thus, assessment of phytoremediation efficiency might be inaccurate if referencing with respect to PAH concentrations in soil without considering the aging effect.

Many previous PAH phytoremediation studies were conducted with freshly contaminated soils (Chen et al., 2003; Gao et al., 2005; Xu et al., 2005), in which the contamination was generally more bioavailable and thus easier to remove. This would be in comparison to a scenario where lower bioavailability would be envisaged, and where PAHs and soils have been in contact for long time. As such, the phytoremediation efficiency observed in previous studies was likely to have been magnified. More informative data on plant uptake and bioavailability of PAHs with aged soils are needed for more accurate evaluation of phytoremediation efficiency, particularly at field sites.

Food crops are often contaminated by various pesticides and organic wastes when exposed to a polluted source (Wennrich et al., 2002). Rice is a staple food in Asia. In China, PAHs occur widely as contaminants from industrial and agricultural sources (Tao et al., 2004). PAHs can easily accumulate in rice straw used as cattle feed, which can eventually be transferred to human beings through the food chain. The anaerobic and reducing environment during the rice growth period in paddy soils is similar to that of a wetland system, thus allowing PAHs to be effectively distributed in soil-plant-water systems. Compared to plants grown in uplands, such as ryegrass, wheat, and maize, the rhizosphere effect of the paddy soil would suggest an important environment for PAH removal. Nonetheless, there have been few reports on the rhizosphere effect on PAH uptake by rice seedlings from aged contaminated paddy soils.

In this study, the distribution and transport mechanisms of three PAHs, naphthalene (NAP), phenanthrene (PHN), and pyrene (PYR), in rice seeding-water-soil systems were investigated, as was the observed effect of rice rhizosphere on PAH removal from soils.

\section{Materials and methods}

\subsection{Soil aging}

The topsoil from a paddy rice field $(0-25 \mathrm{~cm})$ was collected from Jiaxing of Zhejiang Province, China. The total organic carbon of the soil was $2.84 \%$. Following air-drying for $48 \mathrm{~h}$, larger material was removed prior to being passed through a 2 -mm sieve.
Table 1

Physicochemical properties of the organic compounds used in experiments ${ }^{\mathrm{a}}$

\begin{tabular}{llllll}
\hline Compound & Abbreviation & MW & $S_{\mathrm{w}}$ & $H_{\mathrm{c}}$ & $\log K_{\mathrm{ow}}$ \\
\hline Naphthalene & NAP & 128.2 & 31.7 & 43.0 & 3.36 \\
Phenanthrene & PHN & 178.2 & 1.29 & 4.0 & 4.46 \\
Pyrene & PYR & 202.3 & 0.135 & 1.1 & 4.88 \\
\hline
\end{tabular}

MW = molecular weight; $S_{\mathrm{w}}=$ water solubility at $25^{\circ} \mathrm{C}(\mu \mathrm{g} / \mathrm{mL}) ; K_{\mathrm{ow}}=$ octanol-water partition coefficient; $H_{\mathrm{c}}=$ Henry's constant, $\mathrm{Pa} \mathrm{m} \mathrm{m}^{3} / \mathrm{mol}$.

${ }^{\text {a }}$ The $S_{\mathrm{w}}, H_{\mathrm{c}}$, and $K_{\mathrm{ow}}$ values are from Mackay and Shiu (1981).

The soil was spiked with a mixture of high-purity NAP, PHN, and PYR purchased from Aldrich Chemical Co. Fundamental physicochemical properties of the compounds are given in Table 1. Solutions of individual PAHs in acetone were prepared and mixed with soil samples. Acetone was evaporated off by stirring the mixture for $12 \mathrm{~h}$. The resulting PAH-spiked soil samples were then mixed with different amounts of the PAH-free soil to give initial spiked concentrations (before aging) of 50-200, 18-72, and 6.6$26.6 \mathrm{~m} \mathrm{~kg}^{-1}$ for NAP, PHN, and PYR, respectively. The following nutrients were then added: $300 \mathrm{mg} \mathrm{kg}^{-1} \mathrm{~N}$ (urea), $20 \mathrm{mg} \mathrm{kg}^{-1} \mathrm{P} \quad\left(\mathrm{KH}_{2} \mathrm{PO}_{4}\right)$, and

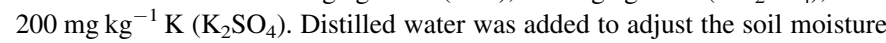
content to $20 \%$ for the equilibration of PAHs. PAH-spiked soils were then packed into polyethylene bags, sealed and incubated for 4 months in the dark at $20-25^{\circ} \mathrm{C}$. During this incubation period, the moisture content (about $80 \%$ water holding capacity) of the PAH-spiked soils was kept constant. The soils were mixed once a week to maintain homogeneity. The PAH-spiked soils, following aging, were packed into polyvinylchloride (PVC) pots $(15 \mathrm{~cm}$ in diameter and $15 \mathrm{~cm}$ in height; see Fig. 1). The spiked soils were analyzed for NAP, PHN, and PYR before seedlings were planted.

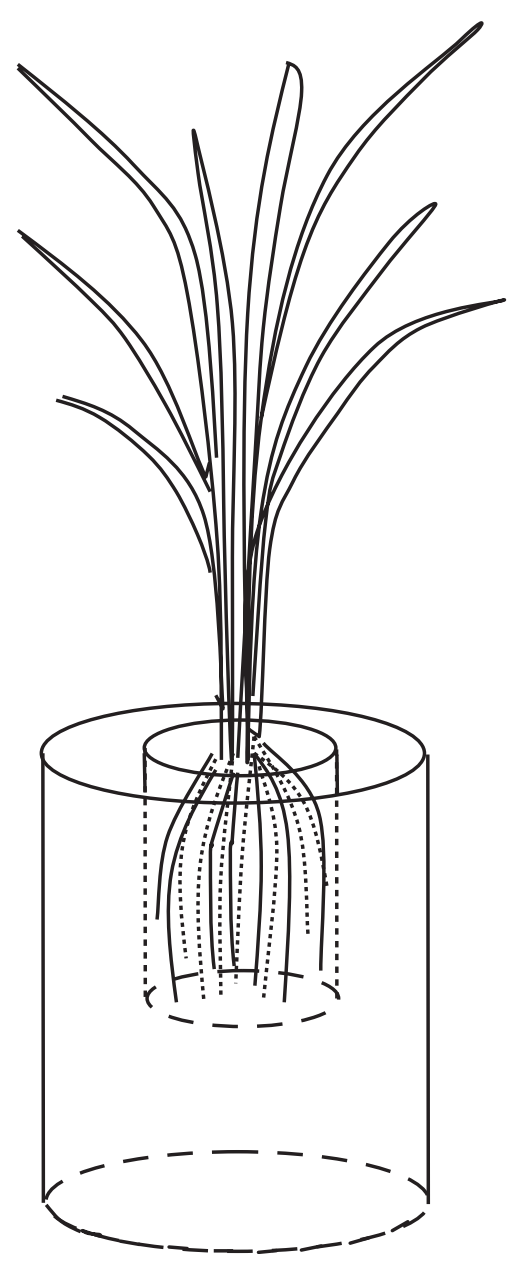

Fig. 1. Rice seedlings grown in soils contained in nylon bag. 


\subsection{Preparation of seedlings}

Seeds of China rice-Jiahua-1 (Oryza sativa L.) were disinfected in $30 \%$ $\mathrm{H}_{2} \mathrm{O}_{2}$ (wt:wt) solution for $10 \mathrm{~min}$, followed by thorough washing with deionized water. The seeds were germinated in moist perlite. Ten days after germination, the seedlings were transferred to a nutrient solution for continuing growth. One week later, seedlings with uniform appearance were selected and transplanted into polyvinylchloride (PVC) pots for the uptake experiments (Fig. 1). At the same time, uniform seedlings were also selected for cultivation in a nutrition solution for 8 weeks for measurement of the seedling properties, such as partition coefficient between plant organic matter and water. The compositions of nutrient solutions were identical to a previous report of $\mathrm{Su}$ and Zhu (2006).

\subsection{Experimental procedure}

Each PVC pot contained $1200 \mathrm{~g}$ of wet-aged soil, $200 \mathrm{~g}$ of which was placed in a $40 \mu \mathrm{m}$-aperture nylon bag that was surrounded by the remaining $1000 \mathrm{~g}$ of soil (Fig. 1). One rice seedling was planted within each nylon bag. The initial contaminant levels in the mixed spiked soils (before aging) were fixed at $50,100,150,200 \mathrm{mg} \mathrm{kg}^{-1}$ dry soil for NAP; 18, 36, 54, $72 \mathrm{mg} \mathrm{kg}^{-1}$ dry soil for PHN; and 7, 13, 20, $267 \mathrm{mg} \mathrm{kg}^{-1}$ dry soil for PYR. Soils without spiked PAHs were also vegetated as controls at the same time. There were four replicates for each treatment. Deionized water was supplied twice every day to ensure soil submergence during the study period. The experiments continued for 8 weeks in a controlled environment with a $14 \mathrm{~h}$ light period $\left(260-350 \mu \mathrm{mol} \mathrm{m}^{-2} \mathrm{~s}^{-1}\right)$ and temperatures of $25^{\circ} \mathrm{C}$ day and $20^{\circ} \mathrm{C}$ night. The relative humidity was fixed at $70 \%$.

\subsection{PAH partitioning into the rice organic components}

The combined dried roots or shoots of rice seedlings, which were cultivated in nutrition solution, were ground (passing 100 mesh), and subsequently used to determine the contaminant partition coefficients between plant organic matter (pom) and water, i.e., the respective $K_{\text {pom }}$ values. In the $K_{\text {pom }}$ determination, fixed quantities of the dried-ground roots or shoots were added to a series of $0.1 \mathrm{M} \mathrm{CaCl}_{2}$ water solutions containing different initial concentrations of a given PAH and $400 \mathrm{mg} / \mathrm{L} \mathrm{NaN}_{3}$; the suspensions were equilibrated for $48 \mathrm{~h}$ and the PAH concentrations in roots or shoots and water after this equilibration period were measured to establish the sorption isotherms. This equilibration period was checked to be for contaminant equilibrium between dry roots or shoots and water, based on previous experimental results (Su and Zhu, 2007).

\subsection{PAH analyses of soil, plant, and solution samples}

Soil pore water was extracted using a ceramic filter and syringe. Soil furthest from the rhizosphere bag, and thus seedling roots, was collected and designated as the non-rhizosphere soil samples, while soils in the rhizosphere bag, and those about $3 \mathrm{~mm}$ surrounding the rice roots, were carefully collected and designated as the rhizosphere soil samples. All soil samples were freeze-dried at $-45^{\circ} \mathrm{C}$ for $48 \mathrm{~h}$ and preserved in a refrigerator at $-20{ }^{\circ} \mathrm{C}$.

The procedure used to extract PAHs from the soils was a modification of those by Kipopoulou et al. (1999), Simonich and Hites (1994), and Gao et al. (2005). Specifically, $4 \mathrm{~g}$ (dry weight) of the ground soil particles $(0.2 \mathrm{~mm}$ aperture) were extracted twice using an ultrasonic crusher (JY92-2D, China) with $40 \mathrm{~mL}$ of mixed dichloromethane and acetone $(5: 3 \mathrm{v} / \mathrm{v})$ after the soil samples were soaked overnight in $40 \mathrm{~mL}$ of the above solvent. The liquid phase was filtered through a filter paper, and eluted through an anhydrous $\mathrm{Na}_{2} \mathrm{SO}_{4}$ column. The eluates were combined, concentrated into a small volume (2$3 \mathrm{~mL}$ ) using a rotary evaporator (Senco, China), dried with a gentle stream of nitrogen, solvated again with hexane four times $(0.5 \mathrm{~mL}$ each time), and cleaned with a silica gel column $(2.5 \mathrm{~g})$ with $20 \mathrm{~mL}$ of 7:3 (v/v) hexane and dichloromethane. Eluates were concentrated using the rotary evaporator method and dried with a gentle stream of nitrogen. The residue was subsequently dissolved in $2 \mathrm{~mL}$ of hexane.
Table 2

Biomasses (gram dry matter) of rice seedlings exposed to various initial concentrations of PAHs (NAP/PHN/PYR, $\mathrm{mg} \mathrm{kg}^{-1}$ dry weight) in soils (mean $\pm \mathrm{SE}, n=4)$

\begin{tabular}{lll}
\hline Initial PAH concentration & Root biomass & Shoot biomass \\
\hline Control & $3.38 \pm 0.17$ & $6.74 \pm 0.54$ \\
$50 / 18 / 7$ & $3.78 \pm 0.22$ & $8.50 \pm 0.50$ \\
$100 / 36 / 14$ & $3.09 \pm 0.31$ & $7.04 \pm 0.56$ \\
$150 / 54 / 20$ & $3.63 \pm 0.12$ & $8.87 \pm 0.48$ \\
$200 / 72 / 27$ & $3.76 \pm 0.14$ & $7.56 \pm 0.28$ \\
Analysis of variance & $\mathrm{NS}^{\mathrm{a}}$ & $\mathrm{NS}$ \\
\hline
\end{tabular}

${ }^{\text {a }}$ NS, not significant; $P>0.05$.

The experimental plants were removed from the soil, carefully rinsed with distilled water to remove residual soil particle on the plant surfaces, blotted dry with a tissue paper, and sectioned into roots and shoots. The relative weight fractions of fresh roots and shoots were determined. Parts of roots and shoots were then freeze-dried at $-45^{\circ} \mathrm{C}$ for $48 \mathrm{~h}$ to determine their water contents. The fresh plant samples were homogenized using a mortar and pestle under liquid nitrogen, and extracted twice using an ultrasonic crusher machine (JY92-2D) with $40 \mathrm{~mL}$ of mixed dichloromethane and acetone. The subsequent plant sample PAH extraction and cleansing procedures were identical as for the soil samples. Water solutions were extracted from the rhizosphere and non-rhizosphere soils using the pore water extraction apparatus, and extracted for the PAHs using $1.0 \mathrm{~mL} n$-hexane.

The quantification and separation of NAP, PHN, and PYR was achieved by an Agilent 6820 gas chromatograph (GC) with a flame ionization detector (FID) using a HP-5 MS capillary column $(0.32 \mathrm{~mm} \times 30 \mathrm{~m} \times 0.25 \mu \mathrm{m})$. A GC oven-temperature program was used to separate the mixed PAHs, which started at $50{ }^{\circ} \mathrm{C}$, held for $2 \mathrm{~min}$, increased to $120^{\circ} \mathrm{C}$ at a rate of $15^{\circ} \mathrm{C} \mathrm{min}{ }^{-1}$, held for $0 \mathrm{~min}$, increased to $230^{\circ} \mathrm{C}$ at a rate of $5^{\circ} \mathrm{C} \mathrm{min}^{-1}$, and held for $1 \mathrm{~min}$. The GC injection-port temperature and the detector temperature were both set at $250^{\circ} \mathrm{C}$. The retention times of NAP, PHN, and PYR under the gas chromatograph in this study are $8.59,20.3$, and $27.1 \mathrm{~min}$, respectively. Average recoveries of NAP, PHN, and PYR based on spiked plant samples (with PAHs at $0.1-3 \mathrm{mg} \mathrm{kg}^{-1}$ ) were $60.6 \pm 6.9,85.7 \pm 3.9$, and $81.3 \pm 3.3 \%(n=6)$, respectively, and those for spiked soil samples (with PAHs at $0.1-10 \mathrm{mg} \mathrm{kg}^{-1}$ ) were $63.5 \pm 20.3,87.9 \pm 2.9$, and $97.8 \pm 3.1 \%(n=4)$, respectively. Detection limits were $0.02,0.02$, and $0.03 \mathrm{mg} \mathrm{kg}^{-1}$ for NAP, PHN, and PYR, respectively.

\subsection{Equilibrium distribution of PAHs in soil-water systems}

Sub-samples of ground rhizosphere soils (passing 35 mesh sieve) were added to a series of $0.1 \mathrm{M} \mathrm{CaCl}_{2}$ water solutions containing different initial amounts of a given PAH and $400 \mathrm{mg} / \mathrm{L} \mathrm{NaN} \mathrm{N}_{3}$; the suspensions were equilibrated for $72 \mathrm{~h}$ and the PAH concentrations in soil and water after this equilibration were measured to establish the sorption isotherms. This equilibration period was checked to be sufficient for contaminant equilibrium between soil and water.

Table 3

PAH concentrations in aged soils before planting with rice seedlings $\left(\mathrm{mg} \mathrm{kg}^{-1}\right)$ (mean $\pm \mathrm{SE}, n=4)$

\begin{tabular}{lllr}
\hline Initial concentration & \multicolumn{3}{l}{ Concentration in aged soils } \\
\cline { 2 - 4 } & NAP & PHN & \multicolumn{1}{l}{ PYR } \\
\hline Control & $0.37 \pm 0.09$ & $0.27 \pm 0.05$ & $0.18 \pm 0.03$ \\
$50 / 18 / 7$ & $1.02 \pm 0.12$ & $1.32 \pm 0.09$ & $2.98 \pm 0.34$ \\
$100 / 36 / 14$ & $1.20 \pm 0.13$ & $2.29 \pm 0.15$ & $7.85 \pm 0.83$ \\
$150 / 54 / 20$ & $1.10 \pm 0.12$ & $3.76 \pm 0.23$ & $18.54 \pm 1.89$ \\
$200 / 72 / 27$ & $1.42 \pm 0.14$ & $4.77 \pm 0.28$ & $18.01 \pm 1.84$ \\
Analysis of variance & NS & $* * *$ & $* * *$
\end{tabular}

$* * * P<0.001 ; * * P<0.01 ; * P<0.05$; NS, not significant. 
Table 4

$\mathrm{PAH}$ concentrations in soils after planting with rice seedlings $\left(\mathrm{mg} \mathrm{kg}^{-1}\right)($ mean $\pm \mathrm{SE}, n=4)$

\begin{tabular}{|c|c|c|c|c|c|c|}
\hline \multirow[t]{3}{*}{ Initial concentration } & \multicolumn{6}{|c|}{ Concentration after planting } \\
\hline & \multicolumn{3}{|c|}{ Rhizosphere soils } & \multicolumn{3}{|c|}{ Non-rhizosphere soils } \\
\hline & NAP & PHN & PYR & NAP & $\mathrm{PHN}$ & PYR \\
\hline Control & $0.32 \pm 0.05$ & $0.14 \pm 0.03$ & $0.14 \pm 0.01$ & $0.28 \pm 0.04$ & $0.17 \pm 0.02$ & $0.14 \pm 0.02$ \\
\hline $50 / 18 / 7$ & $0.42 \pm 0.06$ & $0.62 \pm 0.06$ & $1.07 \pm 0.18$ & $0.41 \pm 0.04$ & $0.75 \pm 0.04$ & $1.31 \pm 0.11$ \\
\hline $100 / 36 / 14$ & $0.79 \pm 0.17$ & $1.35 \pm 0.35$ & $3.54 \pm 0.29$ & $0.64 \pm 0.02$ & $1.22 \pm 0.20$ & $4.48 \pm 0.84$ \\
\hline $150 / 54 / 20$ & $0.50 \pm 0.04$ & $1.44 \pm 0.05$ & $5.40 \pm 0.29$ & $0.57 \pm 0.01$ & $1.57 \pm 0.12$ & $6.31 \pm 0.49$ \\
\hline $200 / 72 / 27$ & $0.71 \pm 0.13$ & $2.09 \pm 0.19$ & $6.51 \pm 0.24$ & $0.76 \pm 0.16$ & $2.50 \pm 0.30$ & $8.34 \pm 0.99$ \\
\hline Analysis of variance & NS & $* *$ & $* * *$ & NS & $*$ & $* * *$ \\
\hline
\end{tabular}

$* * * P<0.001 ; * * P<0.01 ; * P<0.05 ; \mathrm{NS}$, not significant.

\subsection{Statistical analyses}

Analysis of variance (ANOVA) was performed using SPSS (version 13.0). One-way analysis of the variance was carried out on the PAH concentrations.

\section{Results and discussion}

\subsection{Plant biomass}

Both roots and shoot biomasses did not show significant changes when seedlings were exposed to increasing concentrations of the three PAHs, in comparison to the control (Table 2). The PAH concentrations in soils exhibited little toxicity to rice seedlings.

\subsection{PAH concentrations in soils}

The measured concentrations of NAP, PHN, and PYR in soil decreased significantly after the PAHs were aged for 4 months. More than 98, 95, and 30\% of NAP, PHN, and PYR, respectively, were lost from spiked soils during the aging period (Table 3). The NAP, PHN, and PYR levels in the initial spiked soils showed significant differences between the four treatments $(P<0.001)$. The PHN and PYR levels in aged soils correlated well with those in initial spiked soils, while the NAP levels in aged soils were not well correlated with the initial levels $\left(R^{2}<0.6\right)$ and the results with aged soils showed no significant difference among the four treatments $(P>0.05)$. These results indicated that NAP was more prone to loss than PHN and PYR in accordance with their physiochemical properties (Table 1). As a class of persistent pollutants, only a small quantity of PAHs could be degraded by soil microorganisms during the experimental period. The dissipation of PAHs in soils resulted primarily from a direct volatilization, as dictated by their Henry's constants $(H)$ and partition coefficients with soil organic matter $\left(K_{\mathrm{oc}}\right)$ (Chiou et al., 1998).

The PAH concentrations in rhizosphere soils and non-rhizosphere soils after the 8 weeks planting were listed in Table 4 . The concentrations of NAP and PHN in rhizosphere soils showed no significant difference with those in non-rhizosphere soils, whereas the PYR concentrations in rhizosphere soils (except for the controls) were significantly lower than those in non-rhizosphere soils. Thus, the rice rhizosphere had a significant effect on the PYR removal.

Compared to the corresponding levels in soils before planting, concentrations of NAP, PHN, and PYR in rhizosphere soils with different treatments decreased by 13.5-58.8, 48.1-61.7, and 22.2-70.9\% (Table 5), respectively. The decreases in concentrations of the three PAHs in control soils (those without spiked PAHs) were less than those in aged spiked soils, with there being no significant differences in PAH levels between rhizosphere and non-rhizosphere soils. These results indicated that the bioavailability of PAHs in the control soil was far less than that within the artificial spiked soil. However, the decreases in bioavailability of PAHs with both rhizosphere and non-rhizosphere soils were not correlated with the initial PAH concentrations.

\subsection{PAHs concentrations in soil solution}

Due to the soils being submerged during the planted period, the concentrations of PAHs in soils and soil solutions should

Table 5

Reduction of PAH concentrations in soils after planting with rice seedlings

\begin{tabular}{|c|c|c|c|c|c|c|}
\hline \multirow[t]{3}{*}{ Initial concentration } & \multicolumn{6}{|c|}{ Concentration reduction $(\%)$} \\
\hline & \multicolumn{3}{|c|}{ Rhizosphere soils } & \multicolumn{3}{|c|}{ Non-rhizosphere soils } \\
\hline & NAP & PHN & PYR & NAP & PHN & PYR \\
\hline Control & $13.5 \pm 8.2$ & $48.1 \pm 11.1$ & $22.2 \pm 4.0$ & $24.3 \pm 10.4$ & $37.2 \pm 7.9$ & $22.2 \pm 2.2$ \\
\hline $50 / 18 / 7$ & $58.8 \pm 5.5$ & $53.0 \pm 4.3$ & $64.1 \pm 5.9$ & $59.8 \pm 3.8$ & $43.2 \pm 2.9$ & $56.0 \pm 3.6$ \\
\hline $100 / 36 / 14$ & $48.5 \pm 3.4$ & $56.2 \pm 2.4$ & $54.9 \pm 4.2$ & $46.7 \pm 1.5$ & $46.9 \pm 8.6$ & $42.9 \pm 6.7$ \\
\hline $150 / 54 / 20$ & $54.5 \pm 3.9$ & $61.7 \pm 1.7$ & $70.9 \pm 1.6$ & $48.2 \pm 1.3$ & $58.2 \pm 3.2$ & $66.0 \pm 2.6$ \\
\hline $200 / 72 / 27$ & $50.0 \pm 8.9$ & $56.2 \pm 3.9$ & $63.9 \pm 1.3$ & $46.5 \pm 11.5$ & $47.6 \pm 6.2$ & $53.7 \pm 5.5$ \\
\hline Analysis of variance & NS & NS & NS & NS & NS & NS \\
\hline
\end{tabular}

$* * * P<0.001 ; * * P<0.01 ; * P<0.05 ; \mathrm{NS}$, not significant. 


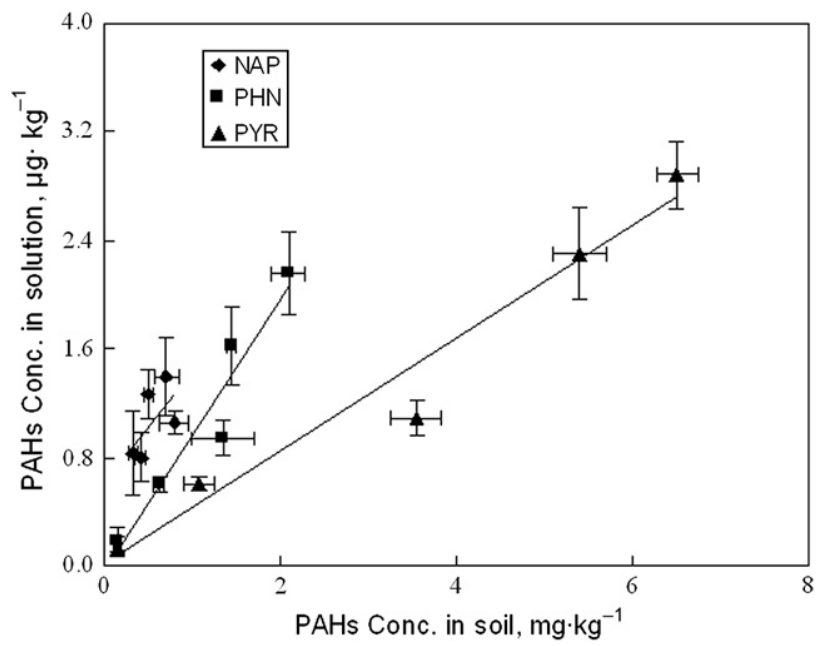

Fig. 2. Relationship of PAH concentrations in external solution and soil.

approximately approach the equilibrium values. Thus, the rhizosphere soil solutions, separated from the soil by centrifugation of the mixture at $3000 \mathrm{~g}$ after 72-h equilibration, were considered as the soil pore water in contact with the rice seedling roots. As noted, the concentrations of individual PAHs in pore water below their solubilities were well related to their concentrations in soils (Fig. 2).

\subsection{Concentrations of PAHs in plants}

Concentrations of PAHs in rice roots were higher than those in shoots (Table 6). PHN and PYR concentrations in roots increased proportionally with those in external solution (soil pore water) and in rhizosphere soils (Figs. 3 and 4). The observed distribution coefficients (the ratios of PAH concentrations in roots to those in soils or external solutions) increased with increasing $\log K_{\text {ow }}$ values of the compounds. Similar correlations for other contaminants in plant roots and external solution were observed (Briggs et al., 1982; Li et al., 2002). These phenomena showed that the accumulation of PAHs by rice roots was influenced by the hydrophobic

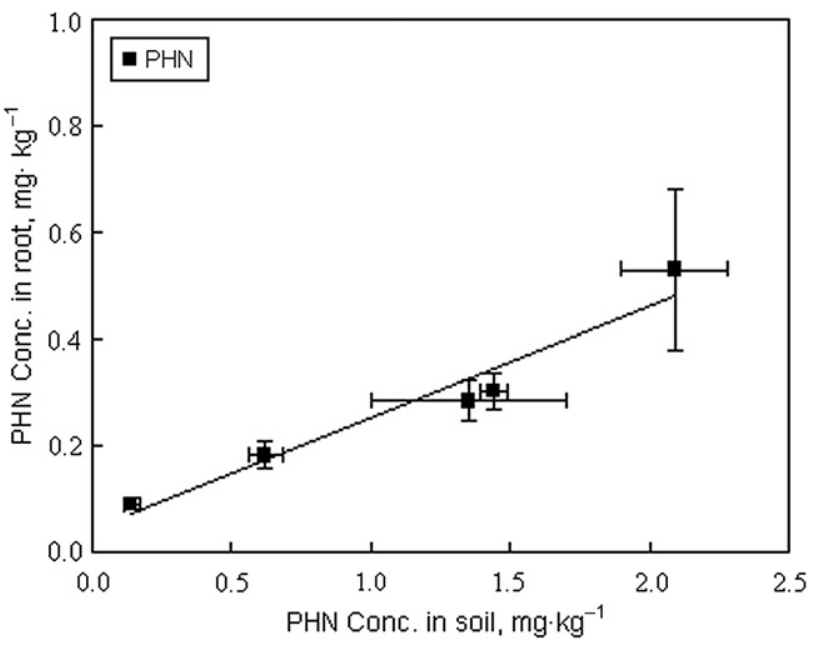

Fig. 3. Relationship of PHN concentrations in soil and rice roots.

components of plant roots, such as lipids ( $\mathrm{Li}$ et al., 2005; Barbour et al., 2005).

However, the concentrations of the three PAHs in rice shoots showed no significant differences with various treatments and were not correlated with those in rice roots. These results suggested that the transport of contaminants from roots to shoots through xylem contributed little to the accumulation of PAHs by shoots. A previous study indicated that PHN and anthracene translocate slowly into plant roots, where PHN is translocated only up to $1500 \mu \mathrm{m}$ in length over a 56-day period (Wild et al., 2005). The longitudinal movement of both PHN and anthracene was not observed to extend beyond the root base (Wild et al., 2005). The direct uptake via a gas-phase transfer would seem to be the more likely and efficient way for rice shoots to accumulate PAHs. Previous studies indicate that PAHs, such as PHN, could enter plant leaves from the atmosphere, accumulating into wax plugs of stomata and on external surfaces of the stomatal pores, from where they diffuse through cuticles into the epidermis to reside ultimately on the cell walls (Wild et al., 2006).

In the present experiments, the observed uptake coefficients of NAP, PHN, and PYR within rice roots were 86, 20, and

Table 6

PAH concentrations in rice seedlings ( $\mathrm{ng} \mathrm{g}^{-1}$, dry weight)

\begin{tabular}{|c|c|c|c|c|}
\hline \multirow[t]{2}{*}{ Sample } & \multirow[t]{2}{*}{ Initial concentration } & \multicolumn{3}{|c|}{ Concentrations } \\
\hline & & NAP & PHN & PYR \\
\hline Shoots & $\begin{array}{l}\text { Control } \\
50 / 18 / 7 \\
100 / 36 / 14 \\
150 / 54 / 20 \\
200 / 72 / 27\end{array}$ & $\begin{array}{r}30.6 \pm 2.8 \\
39.4 \pm 4.5 \\
41.7 \pm 7.2 \\
37.95 \pm 2.6 \\
49.3 \pm 8.4\end{array}$ & $\begin{array}{l}40.8 \pm 1.5 \\
40.9 \pm 4.7 \\
50.2 \pm 8.9 \\
52.6 \pm 2.6 \\
46.7 \pm 3.5\end{array}$ & $\begin{array}{l}33.7 \pm 7.0 \\
41.0 \pm 5.9 \\
50.4 \pm 6.7 \\
75.6 \pm 5.2 \\
56.5 \pm 6.4\end{array}$ \\
\hline Analysis of variance & & NS & NS & NS \\
\hline Roots & $\begin{array}{l}\text { Control } \\
50 / 18 / 7 \\
100 / 36 / 14 \\
150 / 54 / 20 \\
200 / 72 / 27\end{array}$ & $\begin{array}{r}104.6 \pm 20.7 \\
98.2 \pm 12.3 \\
128.1 \pm 21.8 \\
125.2 \pm 36.6 \\
120.1 \pm 18.7\end{array}$ & $\begin{array}{r}90.5 \pm 11.9 \\
182.0 \pm 24.1 \\
282.4 \pm 38.6 \\
301.5 \pm 35.0 \\
528.1 \pm 152.4\end{array}$ & $\begin{array}{c}78.1 \pm 9.9 \\
187.7 \pm 23.7 \\
491.3 \pm 78.2 \\
1459.5 \pm 154.2 \\
1738.2 \pm 341.3\end{array}$ \\
\hline Analysis of variance & & NS & $*$ & $* * *$ \\
\hline
\end{tabular}

$* * * P<0.001 ; * * P<0.01 ; * P<0.05 ; \mathrm{NS}$, not significant. 


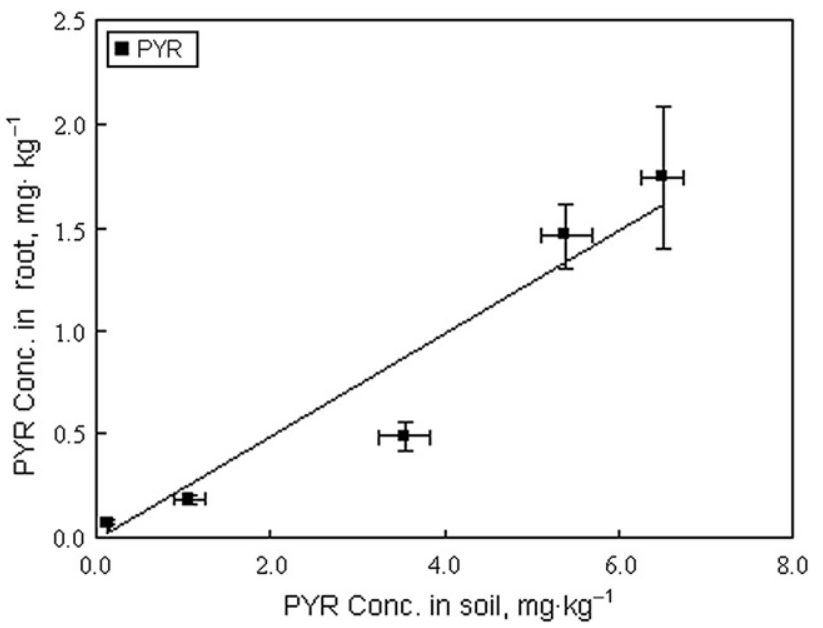

Fig. 4. Relationship of PYR concentrations in soil and rice roots.

$0.06 \%$ of their equilibrium partition coefficients, respectively, with the roots (Table 7). The NAP accumulation by rice roots is near the equilibrium value, while the PYR accumulation is far from it, even though the uptake quantities of PYR by roots were greater than those of NAP. The higher the $K_{\text {ow }}$ of a contaminant, the greater would be the expectancy for it to partition into the organic matter, and thus the lower would be its mass transport within the soil organic matter and plant tissue. Based on the results of Wild et al. (2005), the movement of anthracene within maize cell walls was approximately three times slower than those of PHN. Most current studies on the phytoremediation of soils contaminated with persistent organic pollutants and on the health risk assessments give little attention to the effect of mass transport rates upon plant uptake (Gao et al., 2005; $\mathrm{Xu}$ et al., 2005). In view of the difficulty for PAHs to transfer from rice roots to shoots, the present data indicated that the mass transport rate of contaminants actually limited the rate toward the PAH equilibrium partitioning within plant roots, and subsequently within plant shoots. The mass transport rate of PAHs in plant roots is therefore an important parameter for phytoremediation and health risk assessment.

\subsection{Rhizosphere effects on PAH concentrations}

After 8 weeks, the concentrations of NAP, PHN, and PYR in non-rhizosphere soils (except for control soils) decreased by $50.5 \pm 3.1, \quad 48.9 \pm 2.9, \quad$ and $54.7 \pm 4.7 \%$, respectively,

Table 7

Sorption isotherms of PAHs with dry rice roots and shoots

\begin{tabular}{lllrl}
\hline Sample & Compound & Isotherm equation $^{\mathrm{a}}$ & \multicolumn{1}{c}{$K_{\text {pom }}$} & \multicolumn{1}{l}{$R^{2}$} \\
\hline Roots & NAP & $C_{\mathrm{p}}=136.8 C_{\mathrm{e}}$ & 136.8 & 0.965 \\
& PHN & $C_{\mathrm{p}}=1724.2 C_{\mathrm{e}}$ & 1724.2 & 0.977 \\
& PYR & $C_{\mathrm{p}}=9091.4 C_{\mathrm{e}}$ & 9091.4 & 0.975 \\
\multirow{5}{*}{ Shoots } & NAP & $C_{\mathrm{p}}=222.8 C_{\mathrm{e}}$ & 222.8 & 0.993 \\
& PHN & $C_{\mathrm{p}}=2279.5 C_{\mathrm{e}}$ & 2279.5 & 0.956 \\
& PYR & $C_{\mathrm{p}}=16,051.2 C_{\mathrm{e}}$ & $16,051.2$ & 0.980 \\
\hline
\end{tabular}

\footnotetext{
${ }^{\text {a }} C_{\mathrm{p}}$, PAH concentrations in rice roots at equilibrium; $C_{\mathrm{e}}, \mathrm{PAH}$ concentrations in external solution at equilibrium; $K_{\text {pom }}$, equilibrium partition coefficients of PAHs between plant organic matter and external solution.
}

compared to their concentrations before planting. These decreases were used as the dissipation rates of PAHs in non-rhizosphere soils through evaporation and degradation during the study period. The concentrations of NAP, PHN, and PYR in rhizosphere soils decreased by $53.4 \pm 2.9,56.8 \pm 1.7$, and $64.0 \pm 2.2 \%$, respectively, compared to the initial levels. The plants grown in soil had no significant effect on the decreased concentrations of NAP in soil. However, the decrease in PYR and PHN concentrations was slightly greater in rhizosphere than in non-rhizosphere soils (Table 5). The contribution of rice seedlings to the PYR concentration decreased in rhizosphere soils, being less than $15 \%$ (calculated by subtracting the PYR concentration decreases in non-rhizosphere soils). The plant uptake for PYR removal from rhizosphere soils contributed about $0.24 \%$, according to the PYR accumulation into rice roots and the dry weight of soils. Thus the plant-promoted rhizosphere microbial biodegradation contributed $14 \%$ to the total PYR decrease in rhizosphere soils. These results indicated that rice roots have less rhizosphere effect on the PAH removal than other plant species, such as ryegrass or white clover (Yang et al., 2007). This was hypothesized to be due to typical anaerobic conditions of the paddy fields limiting aerobic PAH degradation.

\section{Conclusion}

There were different rates of transport for NAP, PHN, and PYR to rice roots or shoots from soil. PAHs may be taken up by rice roots via passive processes to subsequently accumulate into the root organic matter. The accumulation of PAHs was well correlated with PAH concentrations in rhizosphere soils, or soil solution. However, PAH uptake by rice shoots appeared to occur mainly by direct uptake from the atmosphere. Because of the high tendency of PAHs in soil solution to reach partition equilibria with adjacent root organic matter, and the low PAH mass transport rates, it was difficult for PAHs to translocate from roots to shoots. Therefore, for soils contaminated with PAHs, both the plant uptake capacity and the PAH mass transport rate must be taken into account to assess the phytoremediation efficiency and the human health risk. Results from the present study indicated that contributions of plant uptake and rhizosphere effect to remove PAHs from soils are relatively insignificant for NAP and PHN, and amount for PYR only to 0.24 and $14 \%$, respectively.

\section{Acknowledgements}

This research was financially supported by the Ministry of Science and Technology (2002CB410808), the National Scientific Foundation of China (20667003). We thank Dr Z. Hickman for his critical reading of the manuscript and improving the English.

\section{References}

Alexander, M., 2000. Aging, bioavailability, and overestimation of risk from environmental pollutants. Environmental Science and Technology 34, 4259-4265. 
Brady, C.A.L., Gill, R.A., Lynch, P.T., 2003. Preliminary evidence for the metabolism of benzo(a) pyrene by Plantago lanceolata. Environmental Geochemistry and Health 25 (1), 131-137.

Bi, X.H., Sheng, G.Y., Peng, P., Chen, Y., Zhang, Z., Fu, J., 2003. Distribution of particulate- and vapor-phase $n$-alkanes and polycyclic aromatic hydrocarbons in urban atmosphere of Guangzhou, China. Atmospheric Environment 37, 289-298.

Barbour, J.P., Smith, J.A., Chiou, C.T., 2005. Sorption of aromatic organic pollutants to grasses from water. Environmental Science and Technology 39, 8369-8373.

Briggs, G.G., Bromilow, R.H., Evans, A.A., 1982. Relationships between lipophilicity and root uptake and translocation of non-ionised chemicals by barley. Pesticide Science 13, 495-504.

Chen, Y.C., Banks, M.K., Schwab, A.P., 2003. Pyrene degradation in the rhizosphere of tall fescue (Festuca arundinacea) and Switchgrass (Panicum virgatum L.). Environmental Science and Technology 37, 5778-5782.

Chiou, C.T., Sheng, G., Manes, M., 2001. A partition-limited model for the plant uptake of organic chemicals from soil and water. Environmental Science and Technology 35, 1437-1444.

Chiou, C.T., McGroddy, S.E., Kile, D.E., 1998. Partition characteristics of polycyclic aromatic hydrocarbons on soils and sediments. Environmental Science and Technology 32, 264-269.

Fismes, J., Perrin-Ganier, C., Empereur-Bissonnet, P., Morel, J.L., 2002. Soilto-root transfer and translocation of polycyclic aromatic hydrocarbons by vegetables grown on industrial contaminated soils. Journal of Environmental Quality 31 (5), 1649-1656.

Gao, Y., Zhu, L.Z., Ling, W., 2005. Validation of the partition-limited model for plant uptake of organic chemicals from soil and water. Science of the Total Environment 336 (1-3), 171-172.

Jones, K.C., Stratford, J.A., Waterhouse, K.S., Vogt, N.B., 1989. Organic contaminants in Welsh soils: polynuclear aromatic hydrocarbons. Environmental Science and Technology 23, 540-550.

Kipopoulou, A.M., Manoli, E., Samara, C., 1999. Bioconcentration of PAHs in vegetable grown in an industrial area. Environmental Pollution 106, 369-380.

Kamath, R., Schnoor, J.L., Alvarez, P.J.J., 2005. Rhizodeposition on the fate of phenanthrene in aged contaminated soil. Environmental Science and Technology 39, 9669-9675.

Li, H., Sheng, G., Sheng, W.T., Xu, O.Y., 2002. Uptake of trifluralin and lindane from water by ryegrass. Chemosphere 48, 335-341.

Li, H., Sheng, G., Chiou, C.T., Xu, O.Y., 2005. Relation of organic contaminant equilibrium sorption and kinetic uptake in plants. Environmental Science and Technology 39, 4864-4870.

Mackay, D., Shiu, W.Y., 1981. A critical review of Henry's law constants for chemicals of environmental interest. Journal of Physical and Chemical Reference Data 10, 1175-1199.

MacLeod, C., Semple, K., 2000. Influence of contact time on extractability and degradation of pyrene in soils. Environmental Science and Technology 34, $4952-4957$
Nam, K., Kim, J.Y., 2002. Role of loosely bound humic substances and humin in the bioavailability of phenanthrene aged in soil. Environmental Pollution 118, 427-433.

Northcott, G.L., Jones, K.C., 2001. Partitioning, extractability, and formation of nonextractable PAH residues in soil. I. Compound differences in aging and sequestration. Environmental Science and Technology 35, 11031110 .

Reid, B.J., Jones, K.C., Semple, K.T., 2000. Bioavailability of persistent organic pollutants in soils and sediments - a perspective on mechanisms, consequences, and assessment. Environmental Pollution 108, 103-112.

Rentz, J.A., Alvarez, P.J.J., Schnoor, J.L., 2004. Repression of Pseudomonas putida phenanthrene-degrading activity by plant root extracts and exudates. Environmental Microbiology 6 (6), 574-583.

Simonich, S.L., Hites, R.A., 1994. Vegetation-atmosphere partitioning of polycyclic aromatic hydrocarbons. Environmental Science and Technology 28, 939-943.

Su, Y.H., Zhu, Y.G., 2006. Bioconcentration of atrazine and chlorophenols into roots and shoots of rice seedlings. Environmental Pollution 139, 32-39.

Su, Y.H., Zhu, Y.G., 2007. Transport mechanisms for the uptake of organic compounds by rice (Oryza sativa) roots. Environmental Pollution 148, 94-100.

Shor, L.M., Kosson, D.S., Rockne, K.J., Young, L.Y., Taghon, G.L., 2004. Combined effects of contaminant desorption and toxicity on risk from PAH contaminated sediments. Risk Analysis 24 (5), 1109-1120.

Trapp, S., 2004. Plant uptake and transport model for neutral and ionic chemicals. Environmental Science and Pollution Research 11, 33-39.

Tao, S., Cui, Y.H., Xu, F.L., Li, B.G., Cao, J., Liu, W.X., Schmitt, G., Wang, X.J., Shen, W.R., Qing, B.P., Sun, R., 2004. Polycyclic aromatic hydrocarbons (PAHs) in agricultural soil and vegetables from Tianjin. Science of the Total Environment 320, 11-24.

Wild, E., Dent, J., Tomas, G.O., Jones, K.C., 2005. Direct observation of organic contaminant uptake, storage, and metabolism with plant roots. Environmental Science and Technology 39, 3695-3702.

Wild, E., Dent, J., Thomas, G.O., Jones, K.C., 2006. Visualizing the air-to-leaf transfer and within-leaf movement and distribution of phenanthrene: further studies utilizing two-photon excitation microscopy. Environmental Science and Technology 40, 907-916.

Wennrich, L., Popp, P., Zeibig, M., 2002. Polycyclic aromatic hydrocarbon burden in fruit and vegetable species cultivated in allotments in an industrial area. International Journal of Environmental Analytical Chemistry 82 (10), 677-690

Xu, S.Y., Chen, Y.X., Lin, Q., Wu, W.X., Xue, S.G., Shen, C.F., 2005. Uptake and accumulation of phenanthrene and pyrene in spiked soils by Ryegrass (Lolium perenne L.). Journal of Environmental Sciences (China) 17 (5), 817-822.

Yang, H., Su, Y.H., Zhu, Y.G., Chen, M.M., Chen, B.D., Liu, Y.X., 2007. Influences of polycyclic aromatic hydrocarbons (PAHs) on soil microbial community composition with or without vegetation. Journal of Environmental Science and Health Part A 42 (1), 65-72. 